\title{
The Effect of Vitamin E Deficiency on Some Erythrocyte Membrane Properties
}

\author{
Kensuke KAMEDA, ${ }^{1 *}$ Makoto IMAI, ${ }^{2}$ and Masanori SENJO ${ }^{1}$ \\ ${ }^{1}$ Department of Biochemistry and ${ }^{2}$ Department of Anesthesiology, \\ School of Medicine, University of Hokkaido, \\ Sapporo 060, Japan
}

(Received March 9, 1985)

\begin{abstract}
Summary The erythrocytes from the vitamin E-deficient rats showed no changes in comparison with the erythrocytes from the vitamin Esupplemented rats in lipid peroxides, membrane fluidity, lipid composition, and activities of defensive enzymes against the lipid peroxide formation. Once erythrocytes from vitamin E-deficient rats were exposed to $\mathrm{H}_{2} \mathrm{O}_{2}$, the erythrocyte membrane fluidity was significantly reduced, which was presumed to be accompanied by an increase in the hemolysis and lipid peroxide formation. Large decreases in arachidonic acid and phospholipid were also observed. These findings suggest that the reduced membrane fluidity is due to the loss of phospholipid from the erythrocytes, and raises the possibility that the reduced fluidity might contribute to the peroxidative hemolysis of the vitamin E-deficient rat erythrocytes.
\end{abstract}

Key Words lipid peroxides, vitamin E, membrane fluidity, hemolysis

The peroxidation of unsaturated fatty acids of phospholipids in biological membranes has been considered to be the basis for many pathological phenomena (reviewed in Ref. 1). In vitamin E-deficient animals, for example, lipid peroxides has been implicated in oxidative hemolysis (2-4). Horwitt et al. suggested that the exposure of erythrocytes to $\mathrm{H}_{2} \mathrm{O}_{2}$ enhanced the susceptibility of the lipid structure of the erythrocytes to autoxidation, and that this autoxidation of lipids might lead to hemolysis (2). The quantitative correlation between the erythrocyte membrane lipid peroxide formation and hemolysis was shown by Dodge et al. (4). The authors demonstrated that polyunsaturated fatty acids decreased in the cells treated with $\mathrm{H}_{2} \mathrm{O}_{2}$ according to the lipid peroxide formation which preceded the hemolysis.

Recently, the effect of lipid peroxide formation on the membrane fluidity has been reported (5-7). In the studies employing the phospholipid bilayer $(5,6)$ and the

1 亀田謙介, ${ }^{2}$ 今井 真, ${ }^{1}$ 千丈雅徳

* Present address: Department of Pharmacology, School of Medicine, Case Western Reserve University, Cleveland, Ohio 44106, U.S.A. 
erythrocyte membranes treated with the hemolytic drug, phenylhydrazine (7), a decrease in the membrane fluidity was demonstrated.

However, very few studies have reported the correlation between erythrocyte hemolysis and membrane fluidity. In this study we have examined the effect of vitamin $\mathrm{E}$ deficiency on some membrane properties, e.g. membrane fluidity, hemolysis, and lipid peroxide formation, in order to approach the mechanism by which the damage caused by the exposure of the erythrocytes in the vitamin Edeficient rats to $\mathrm{H}_{2} \mathrm{O}_{2}$ leads to hemolysis.

\section{MATERIALS AND METHODS}

Reagents. 1,6-Diphenyl-1,3,5-hexatriene was purchased from Tokyo Chemical Industry, Ltd. NADPH and NADP were obtained from Kyowa Hakko Kogyo, Ltd. D-Glucose 6-phosphate and glutathione reductase (yeast) were obtained from Oriental Yeast Co., Ltd. Superoxide dismutase (bovine blood, Type I) and (-)-epinephrine (+ bitartrate) were purchased from Sigma Chemical Co.

Animals. Weanling male Wistar-King-Albino rats were fed either the vitamin E-supplemented (234 mg D, L $\alpha$-tocopheryl nicotinate $/ \mathrm{kg}$ ) or deficient (less than $5 \mathrm{mg}$ $\mathrm{D} \alpha$-tocopherol $/ \mathrm{kg}$ ) diets with $8 \%$ stripped corn oil (Oriental Yeast Co., Ltd.) in each case for 10 weeks. Blood was taken by heart puncture in a heparinized syringe. The plasma and erythrocyte vitamin E levels were determined by the fluorometric method of Taylor et al.(8):

Preparation of erythrocyte membranes. The erythrocyte membranes were prepared by osmotic lysis as described by Hanahan and Ekholm (9).

Hemolysis test. Percent hemolysis was determined by the method of Horwitt et al. (2), using $\mathrm{H}_{2} \mathrm{O}_{2}$, at a final concentration of $1.25 \%$.

Lipid peroxides. The lipid peroxides were assayed by measuring malondialdehyde according to the colorimetric method described by Dahle et al. (10). $0.5 \mathrm{ml}$ of $2.5 \%$ erythrocyte suspension in $77 \mathrm{mM} \mathrm{NaCl} / 25 \mathrm{~mm}$ potassium phosphate, $\mathrm{pH} 7.4$, was added to $1 \mathrm{ml} \mathrm{20 \%}$ trichloroacetic acid, and the precipitate was removed by centrifugation. $1 \mathrm{ml}$ of the supernatant was added to $2 \mathrm{ml}$ of $1 \%$ thiobarbituric acid, and this solution was boiled for $15 \mathrm{~min}$. The absorbance which developed in this mixture was measured at $535 \mathrm{~nm}$.

Fluorescense polarization measurements. The labeling procedure to the erythrocyte membranes with diphenyl hexatriene as a probe was carried out by the method of Shinitzky and Inbar (11). $1 \mu \mathrm{M}$ Diphenylhexatriene in $77 \mathrm{~mm} \mathrm{NaCl} / 25 \mathrm{~mm}$ potassium phosphate, $\mathrm{pH} 7.4$, was mixed with an equal volume of the erythrocytes (final concentration $0.09-0.13 \mathrm{mg}$ protein $/ \mathrm{ml}$ ). The mixtures were incubated at $37^{\circ} \mathrm{C}$. for $1 \mathrm{~h}$. The steady-state measurement of fluorescence polarization was carried out at $37^{\circ} \mathrm{C}$ in triplicate, using the Hitachi Fluorescence Spectrophotometer $650-60$ which directly records the fluorescence polarization

$$
P=\frac{I_{\mathrm{Vv}}-I_{\mathrm{VH}}}{I_{\mathrm{vv}}+I_{\mathrm{vH}}}
$$


where $I_{\mathrm{VV}}$ and $I_{\mathrm{VH}}$ are the intensities of the fluorescence emitted in parallel and perpendicular to the exciting beam. Diphenylhexatriene was excited at $357 \mathrm{~nm}$, and the fluorescence was detected at $426 \mathrm{~nm}$ through a $390-\mathrm{nm}$ cut off filter. Timeresolved nanosecond fluorescence measurement was carried out and observed decays of fluorescence polarization following pulsed excitation were analyzed according to the method of Kinoshita et al.(12).

Erythrocyte membrane lipid analysis. Lipids were extracted from a portion of the erythrocytes suspension with chloroform-methanol 2:1 (by vol.)(13). The phospholipid was measured according to the method of Bartlett(14). The separation of the phospholipids was carried out on Kieselgel 60 (Merck) with a solution of chloroform-methanol-acetic acid-water $25: 15: 4: 2$ (by vol.). Each phospholipid was visualized with an exposure of iodine vapor, scrapped from the plate, and measured as inorganic phosphorus (14). The cholesterol was measured by cholesterol oxidase (Kit-Determiner TC “555”, Kyowa Hakko Kogyo, Ltd.).

Enzyme assay. The activities of catalase (15), glutathione peroxidase (16), superoxide dismutase (17) and glucose-6-phosphate dehydrogenase (18) of the erythrocyte membranes and cytosol, were determined according to the methods described before. The hemoglobin free cytosol for the measurement of superoxide dismutase activity was prepared according to the method of McCord and Fridovich (19) with a modification. $2 \mathrm{ml}$ of erythrocyte cytosol was applied to a $1.6 \times 5 \mathrm{~cm}$ column of DE 52 (Whatman), previously equilibrated with $2.5 \mathrm{~mm}$ potassium phosphate buffer, $\mathrm{pH}$ 7.5. The column was washed with the same buffer, then non-hemoglobin protein fraction which contaired superoxide dismutase activity was eluted with $0.3 \mathrm{~m}$ potassium phosphate buffer, $\mathrm{pH}$ 7.5. The erythrocyte membranes were treated with bath type ultrasonicator prior to the assay of enzyme activities. Protein was assayed by the method of Lowry et al. (20).

\section{RESULTS}

\section{Effect of vitamin E deficiency}

The rats receiving the vitamin E-deficient diet exhibited $97 \%$ erythrocyte hemolysis in the peroxide hemolysis test, while the erythrocytes from vitamin Esupplemented rats exhibited essentially no hemolysis (Table 1). The lipid peroxide formation as measured with TBA was determined, and no significant difference was observed between vitamin E-deficient and vitamin E-supplemented rats (Table 1). The lipid composition of the erythrocytes was also determined. The relative fatty acid composition, cholesterol and phospholipid amounts, and phospholipid composition were not significantly different in the vitamin E-deficient and vitamin Esupplemented rats (data not shown). The steady-state measurements of fluorescence polarization also showed no significant difference in the erythrocyte membranes from the two groups. No changes in the activities of catalase, glutathione peroxidase, superoxide dismutase, and glucose-6-phosphatase, which play the defensive roles in lipid peroxide formation(21), were found in the erythrocyte 
Table 1. Tocopherol, hemolysis, lipid peroxidation, and fluidity in vitamin E-deficient and vitamin E-supplemented rat erythrocytes.

\begin{tabular}{|c|c|c|c|c|}
\hline Diet condition & $\begin{array}{c}\text { Tocopherol } \\
\text { (ng/mg protein) }\end{array}$ & $\begin{array}{c}\text { Hemolysis } \\
(\%)\end{array}$ & $\begin{array}{l}\text { Lipid peroxidation } \\
\text { (nmol malondial- } \\
\text { dehyde/mg protein) }\end{array}$ & $\mathbf{P}^{\mathbf{b}}$ \\
\hline+ Vitamin E (4) & $21.4 \pm 3.8$ & 0 & $0.31 \pm 0.04$ & $0.292 \pm 0.009$ \\
\hline - Vitamin E (4) & $4.5 \pm 4.5$ & $97.0 \pm 3.8$ & $0.30 \pm 0.04$ & $0.282 \pm 0.006$ \\
\hline
\end{tabular}

${ }^{a}$ Values are expressed as means \pm SD for the number of animals given in parentheses.

${ }^{b}$ Membrane fluidity is expressed as the degree of fluorescence polarization (P).

Table 2. Activities of catalase, glutathione peoxidase, superoxide dismutase, and glucose-6-phosphate dehydrogenase in erythrocyte membranes and cytosol from vitamin E-deficient and vitamin E-supplemented rats.

\begin{tabular}{|c|c|c|c|c|}
\hline & \multicolumn{2}{|c|}{ Membrane $^{a}$} & \multicolumn{2}{|c|}{ Cytosol $^{\mathrm{a}}$} \\
\hline & +V.E (4) & -V.E (4) & + V.E (4) & - V.E (4) \\
\hline $\begin{array}{l}\text { Catalase } \\
\text { (mol } \mathrm{H}_{2} \mathrm{O}_{2} \text { decomposed } / \\
\mathrm{min} / \mathrm{mg} \text { protein) }\end{array}$ & $317.0 \pm 33.9$ & $275.5 \pm 69.9$ & $80.6 \pm 2.8$ & $94.2 \pm 17.5$ \\
\hline $\begin{array}{l}\text { Glutathione peroxidase } \\
\text { (mol NADPH decom- } \\
\text { posed/min/mg protein) }\end{array}$ & $3.18 \pm 0.15$ & $3.33 \pm 0.69$ & $0.38 \pm 0.02$ & $0.40 \pm 0.08$ \\
\hline $\begin{array}{l}\text { Superoxide dismutase } \\
\text { (unit/mg non-hemoglobin } \\
\text { protein) }\end{array}$ & N.D. ${ }^{b}$ & N.D. ${ }^{b}$ & $1,098.2 \pm 166.4$ & $1,027.1 \pm 150.6$ \\
\hline $\begin{array}{l}\text { Glucose-6-phosphate } \\
\text { dehydrogenase } \\
\text { (mol NADPH formed/ } \\
\text { min/mg protein) }\end{array}$ & $0.022 \pm 0.008$ & $0.013 \pm 0.002$ & $0.013 \pm 0.001$ & $0.012 \pm 0.001$ \\
\hline
\end{tabular}

${ }^{a}$ Values are expressed as means \pm SD for the number of animals given in parentheses. There were no significant differences as evaluated using the Student's $t$-test. ${ }^{b}$ N.D., not detectable.

membranes, as well as the cytosol from the vitamin E-deficient rats, compared with the erythrocytes from the vitamin E-spplemented rats (Table 2).

Lipid peroxides, membrane fluidity, and hemolysis induced by $\mathrm{H}_{2} \mathrm{O}_{2}$ in erythrocytes from vitamin E-deficient rats

The erythrocytes from the vitamin E-deficient rats were incubated with various concentrations of $\mathrm{H}_{2} \mathrm{O}_{2}$. The parallel increase in the hemolysis, lipid peroxides, and steady-state fluorescence polarization were observed as shown in Fig. 1. Since a 


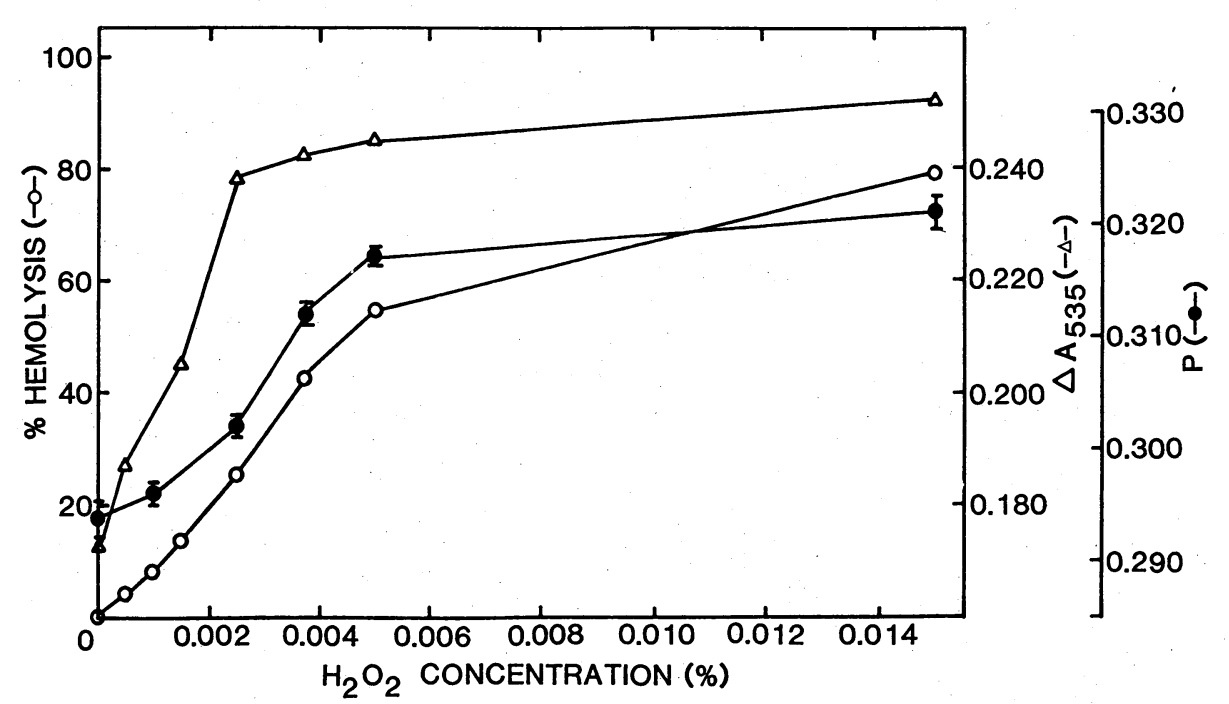

Fig. 1. Effects of $\mathrm{H}_{2} \mathrm{O}_{2}$ on the level of lipid peroxidation, membrane fluidity and hemolysis of the erythrocytes.in vitamin E-deficient rats. Blood was collected and the erythrocytes were washed as described in MATERIALS AND METHODS. The 5\% cell suspension was incubated in a shaking water bath with an equivalent volume of

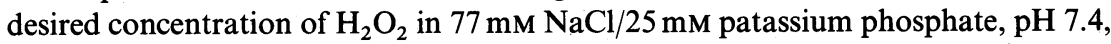
at $37^{\circ} \mathrm{C}$ for $1 \mathrm{~h} .0 .5 \mathrm{ml}$ of this incubation mixture was taken and $1 \mathrm{ml} \mathrm{of} 20 \%$ trichloroacetic acid was added to determine lipid peroxide. The absorbance was measured at $535 \mathrm{~nm} .0 .2 \mathrm{ml}$ of the incubation mixture was taken for measurement of $\mathrm{H}_{2} \mathrm{O}_{2}$-induced hemolysis and $2 \mathrm{ml}$ of $77 \mathrm{mM} \mathrm{NaCl} / 25 \mathrm{mM}$ potassium phosphate, $\mathrm{pH}$ 7.4 , was added. The incubation mixture was then centrifuged at $3,000 \times g$ for $10 \mathrm{~min}$, and the absorbance of the supernatant was measured at $540 \mathrm{~nm}$. For measurement of steady-state fluorescence polarization, $0.2 \mathrm{ml}$ of the incubation mixture was taken. The $2 \mathrm{ml}$ of distilled water containing $2.9 \mu \mathrm{M} \mathrm{D}, \mathrm{L} \alpha$-tocopherol as an antioxidant, was added to this mixture, following the addition of an equivalent volume of $1 \mu \mathrm{M}$ 1,6-diphenyl-1,3,5-hexatriene in $77 \mathrm{mM} \mathrm{NaCl} / 25 \mathrm{~mm}$ potassium phosphate, $\mathrm{pH}$ 7.4. After the incubation at $37^{\circ} \mathrm{C}$ for $1 \mathrm{~h}$, fluorescence polarization was determined. $\triangle$, lipid peroxidation; $O$, hemolysis; $\bullet$, fluorescence polarization $\mathbf{P}$. Each point represents the mean of three experiments, and the standard deviation is indicated by bars.

decrease in the decay time of diphenylhexatriene in peroxidized membranes could lead to an increase in steady-state fluorescence polarization, we determined the decay time with time-resolved nanosecond fluorescence measurement. The decay time of diphenylhexatriene showed no difference in control erythrocyte membranes $(10.4 \mathrm{nsec})$ and peroxidized ones $(10.8 \mathrm{nsec})$. This indicated the increase in steadystate fluorescence polarization was indicative of a decrease in membrane fluidity. 
Table 3. Altered fatty acid composition of erythrocyte membranes treated with $\mathrm{H}_{2} \mathrm{O}_{2}{ }^{a}$

\begin{tabular}{cccccc}
\hline & $16: 0$ & $18: 0$ & $18: 1$ & $18: 2$ & $20: 4$ \\
\hline & & \multicolumn{5}{c}{$\left(\mathrm{mol}^{\mathrm{o}}\right)^{\mathrm{c}}$} \\
$-\mathrm{H}_{2} \mathrm{O}_{2}$ & $30.1 \pm 0.8$ & $16.6 \pm 0.6^{\mathrm{c}}$ & $12.4 \pm 0.9^{\mathrm{d}}$ & $9.0 \pm 0.4^{\mathrm{c}}$ & $31.9 \pm 2.5^{\mathrm{e}}$ \\
$+\mathrm{H}_{2} \mathrm{O}_{2}{ }^{\mathrm{b}}$ & $30.1 \pm 0.1$ & $15.0 \pm 0.1$ & $11.0 \pm 0.1$ & $8.1 \pm 0.1$ & $15.1 \pm 0.2$ \\
\hline
\end{tabular}

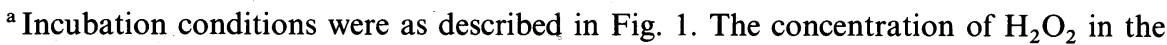
incubation mixture was $0.005 \%$. Incubations were terminated by the addition of 4 volumes of chloroform-methanol 2:1 (by vol.) and the lipid fractions were subsequently extracted. Values are expressed as means \pm SD for 3 experiments. ${ }^{b}$ The percentages in the samples incubated with $\mathrm{H}_{2} \mathrm{O}_{2}$ were recalculated by means of the factor that made the per cent of palmitic acid equal to its value in the samples incubated without $\mathrm{H}_{2} \mathrm{O}_{2}$. ${ }^{\mathrm{c}}$ A significant difference was observed as evaluated using the Student's $t$-test, where $p<0.005$. ${ }^{\mathrm{d}} p<0.01 .{ }^{\mathrm{e}} p<0.0005$.

Alteration of membrane lipids in erythrocytes from vitamin E-deficient rats after treatment with $\mathrm{H}_{2} \mathrm{O}_{2}$

Large decrease in arachidonic acid and phospholipid were observed in the $\mathrm{H}_{2} \mathrm{O}_{2}$-treated erythrocytes (Tables 3 and 4). These findings are consistent with a previous report of Dodge et al.(4). Linoleic acid also slightly decreased. In the phospholipid composition, the amounts of all fractions were lower than those in control systems, and the phosphatidylethanolamine fraction was largely decreased $(22 \%$ of the phosphatidylethanolamine content in the samples incubated without $\mathrm{H}_{2} \mathrm{O}_{2}$ ) (Table 4).

\section{DISCUSSION}

In the erythrocytes, vitamin $\mathrm{E}$ was located in the membranes, where it is proposed to act as an antioxidant in lipid peroxide formation. Although the erythrocytes in the rats receiving the vitamin E-deficient diet showed deep vitamin $\mathrm{E}$ deficiency, we observed neither an increase in lipid peroxides nor an alteration of lipid composition in the erythrocytes. These results, however, could not eliminate the role of vitamin $\mathrm{E}$ as a lipid antioxidant, since the enzymatic defense system was present to minimize the lipid peroxide formation (21). As shown in Table 2, these enzymes were found to be active at the same level in the erythrocytes of both the vitamin E-deficient rats and vitamin E-supplemented rats. Therefore, the onset of the $\mathrm{H}_{2} \mathrm{O}_{2}$-induced hemolysis of the erythrocytes of the vitamin E-deficient rats did not seem to be triggered by the secondary effects, which possibly occurred, due to vitamin E deficiency, such as the change in the distribution of the erythrocyte membrane phospholipids and fatty acids, or the depression of the enzymatic defense system. The $\mathrm{H}_{2} \mathrm{O}_{2}$-induced hemolysis might be due to the lack of antioxidant 


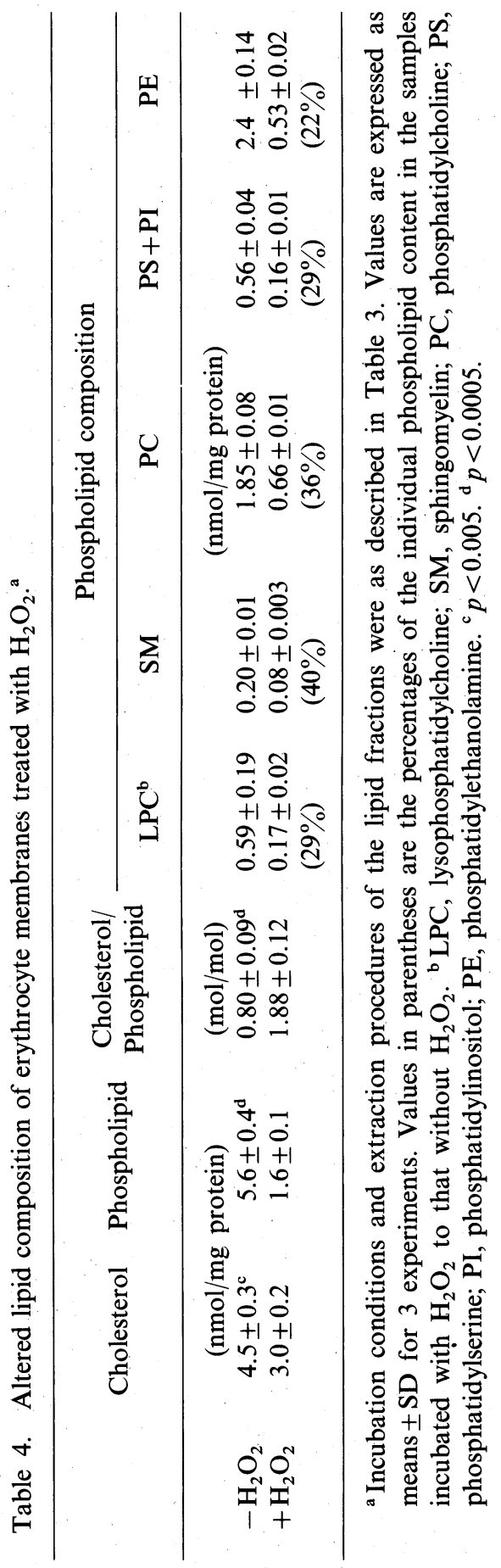


properties of vitamin $\mathrm{E}$, which was supported by the fact that the in vitro addition of vitamin $\mathrm{E}$ to the incubation mixture prevented the hemolysis (4).

The hemolysis of vitamin E-deficient rat erythrocytes is known to be induced by dialuric acid and other oxidants, as well as by $\mathrm{H}_{2} \mathrm{O}_{2}$. Cohen and Heikkila suggested that the cytotoxic effect of dialuric acid was due to the formation of hydroxyl radicals in a mixture of $\mathrm{H}_{2} \mathrm{O}_{2}$ and alloxan which resulted from the oxidation of dialuric acid (22). We have had an interest in the nature of the chemical species which reacted with the erythrocytes in $\mathrm{H}_{2} \mathrm{O}_{2}$-induced hemolysis. We, therefore, used $\mathrm{H}_{2} \mathrm{O}_{2}$ as a hemolytic agent rather than dialuric acid in the present study. In the preliminary studies, mannitol and ethanol, which were the hydroxyl radical scavengers, did not inhibit the $\mathrm{H}_{2} \mathrm{O}_{2}$-induced hemolysis. Although the mechanism is still unclear, the involvement of the hydroxyl radical appears to be excluded in this system.

Gallo-Torres reported that a higher concentration of tocopherol appeared in the lymph when $\alpha$-tocopheryl nicotinate was administered to rats with a thoracic duct fistula than when $\alpha$-tocopheryl acetate was given (23). Therefore $\alpha$-tocopheryl nicotinate was used for vitamin E-supplemented rats in the present study. Suzuki and Nakamura reported that a small percentage of the unhydrolyzed form of $\alpha$ tocopheryl nicotinate appeared in rat erythrocyte membranes after the oral administration (24). It was assumed, therefore, that the action of $\alpha$-tocopheryl nicotinate taken by the rats was revealed mainly in the form of free tocopherol because of the small amount of nicotinate ester in the membranes, although the distribution of the nicotinate ester may be different, due to the modification in structure and polarity, from that of free tocopherol in the membranes.

The decrease in the fluidity in the $\mathrm{H}_{2} \mathrm{O}_{2}$-treated erythrocytes might be explained by the loss of phospholipid from the membranes. It was observed that the arachidonic acid concentration largely decreased in the $\mathrm{H}_{2} \mathrm{O}_{2}$-treated erythrocytes. The decrease in arachidonic acid, caused by lipid peroxide formation, was also shown in liver microsomes by May and McCay (25). They reported that the polyunsaturated fatty acids (primarily arachidonic acid) in phosphatidylethanolamine and phosphatidylcholine were consumed by the NADPH oxidase-catalyzed lipid peroxide formation. The extreme low concentration of the membrane phospholipids in the $\mathrm{H}_{2} \mathrm{O}_{2}$-treated erythrocytes, therefore, seemed to be a result of the peroxidative cleavage of unsaturated fatty acids of the phospholipid molecules. The loss of the phospholipids from the membranes might have resulted in disorganization of the lipid bilayer matrix, and could have caused damage to the cellular function. The change in the amount of cholesterol relative to phospholipids has been shown to alter the fluidity in liposomes and biological membranes(11). In the present study, the cholesterol/phospholipid molar ratio significantly increased from 0.80 to 1.88 , which was mainly due to a decrease in the phospholipid concentration, and this supported the observation that membrane fluidity was reduced in the erythrocytes treated with $\mathrm{H}_{2} \mathrm{O}_{2}$. Our experiments suggest that the reduced membrane fluidity is due to the release of phospholipids from the erythrocytes which 
results from the peroxidative cleavage of arachidonic acid of phospholipids. This study raises the possibility that reduced fluidity might contribute to the peroxidative hemolysis of the vitamin E-deficient rat erythrocytes and requires further investigation.

This work was supported by Grants-in-Aid for Scientific Research from the Ministry of Education, Science and Culture of Japan and by fund from Eisai, Co. We thank Dr. T. Araiso and Professor T. Koyama, The Research Institute of Applied Electricity, University of Hokkaido, for measuring the fluorescence decay time.

\section{REFERENCES}

1) Mead, J. F. (1976): Free radical mechanisms of lipid damage and consequences for cellular membranes, in Free Radicals in Biology, Vol. 1, ed. by Pryor, W. A., Academic Press, Inc., New York, pp. 51-67.

2) Horwitt, M. K., Harvey, C. C., Duncan, G. D., and Wilson, W. C. (1956): Effects of limited tocopherol intake in man with relationships to erythrocyte hemolysis and lipid oxidations. Am. J. Clin. Nutr., 4, 408-419.

3) Fee, J. A., Bergamini, R., and Briggs, R. G. (1975): Observations on the mechanisms of the oxygen/dialuric acid-induced hemolysis of vitamin E-deficient rat red blood cells and the protective roles of catalase and superoxide dismutase. Arch. Biochem. Biophys., 169, 160-167.

4) Dodge, J. R., Cohen, G., Kayden, H. J., and Philips, G. B. (1967): Peroxidative hemolysis of red blood cells from patients with abetalipoproteinemia (acantocytosis). $J$. Clin. Invest., 46, 357-368.

5) Dobretsov, G. E., Borshevskaya, T. A., Petrov, V. A., and Vladimilov, Yu. A. (1977): The increase of phospholipid bilayer rigidity after lipid peroxidation. FEBS Lett., 84, $125-128$.

6) Bruch, R. C., and Thayer, W. S. (1983): Differential effect of lipid peroxidation on membrane fluidity as determined by electron spin resonance probes. Biochim. Biophys. Acta, 733, 216-222.

7) Rice-Evance, C., and Hochstein, P. (1981): Alterations in erythrocyte membrane fluidity by phenylhydrazine-induced peroxidation of lipids. Biochem. Biophys. Res. Commun., 100, 1537-1542.

8) Taylor, S. L., Lamden, M. P., and Tappel, Al. L. (1976): Sensitive fluorometric method for tissue tocopherol analysis. Lipids, 11, 530-538.

9) Hanahan, D. G., and Ekholm, J. E. (1974): The preparation of red cell ghosts (membranes), in Methods in Enzymology, ed. by Fleischer, S., and Packer, L. P., Academic Press, Inc., New York, pp. 168-172.

10) Dahle, L. K., Hill, E. G., and Holman, R. T. (1962): The thiobarbituric acid reaction and the autoxidations of polyunsaturated fatty acid methyl esters. Arch. Biochem. Biophys., 98, 253-261.

11) Shinitzky, M., and Inbar, M. (1976): Microviscosity parameters and protein mobility in biological membranes. Biochim. Biophys. Acta, 433, 133-149.

12) Kinoshita, K., Jr., Kataoka, R., Kimura, Y., Gotoh, O., and Ikegami, A. (1981): Dynamic structure of biological membranes as probed by 1,6-diphenyl-1,3,5hexatriene: a nanosecond fluorescence depolarization study. Biochemistry, 20, 4270-4277.

Vol. 31, No. 5, 1985 
13) Folch, J., Lees, M., and Sloane Stanley, G. H. (1957): A simple method for the isolation and purification of total lipids from animal tissues. J. Biol. Chem., 226, 497-509.

14) Bartlett, G. R. (1959): Phosphorus assay in column chromatography. J. Biol. Chem., 234, 466-468.

15) Bergmyer, H. U., Gawehn, K., and Grassl, M. (1974): in Methods of Enzymatic Analysis, ed. by Bergmyer, H. U., Verlag Chemie, Weinheim, pp. 438-439.

16) Paglia, D. E., and Valentine, W. N. (1967): Studies on the quantitative and qualitative characterization of erythrocyte glutathione peroxidase. J. Lab. Clin. Med., 70, 158-169.

17) Misra, H. P., and Fridovich, I. (1972): The role of superoxide anion in the autoxidation of epinephrine and a simple assay for superoxide dismutase. J. Biol. Chem., 247, $3170-3175$.

18) Bergmyer, H. U., Gawehn, K., and Grassl, M. (1974): in Methods of Enzymatic Analysis, ed. by Bergmyer, H. U., Verlag Chemie, Weinheim, pp. 458-459.

19) McCord, J. M., and Fridovich, I. (1969): Superoxide dismutase. An enzymatic function for erythrocuprein (hemocuprein). J. Biol. Chem., 244, 6049-6055.

20) Lowry, O. H., Rosebrough, N. J., Farr, A. L., and Randall, R. J. (1951): Protein measurements with the Folin phenol reagent. J. Biol. Chem., 193, 265-275.

21) Witting, L. A. (1980): Vitamin E and lipid antioxidants in free-radical-initiated reactions, in Free Radicals in Biology, Vol. IV, ed. by Pryor, W. A., Academic Press, Inc., New York, pp. 295-319.

22) Cohen, G., and Heikkila, R. E. (1974): The generation of hydrogen peroxide, superoxide radical, and hydroxyl radical by 6-hydroxydopamine, dialuric acid, and related cytotoxic agents. J. Biol. Chem., 249, 2447-2452.

23) Gallo-Torres, H. G. (1970): Obligatory role of bile for the intestinal absorption of vitamin E. Lipids, 5, 379-384.

24) Suzuki, N., and Nakamura, T. (1983): Metabolism of the nicotinic acid moiety of $d, l-\alpha-$ tocopheryl nicotinate. J. Nutr. Sci. Vitaminol., 29, 93-103.

25) May, H. E., and McCay, P. B. (1968): Reduced triphosphopyridine nucleotide oxidasecatalyzed alteration of membrane phospholipids. I. Nature of the lipid alterations. $J$. Biol. Chem., 243, 2288-2295. 